\title{
MAGANG MAHASISWA
}

\author{
Ahmad Mustanir \\ STISIP MUHAMMADIYAH RAPPANG \\ DI KANTOR DESA/KELURAHAN
}

\subsection{Latar Belakang}

Kedudukan magang adalah sebagai Mata Kuliah yang wajib diikuti oleh setiap Mahasiswa. Bobot magang ini adalah 1 SKS. Pemikiran yang melatar-belakangi diselenggarakan magang pada umumnya, adalah :

1. Bahwa kemampuan dan keterampilan yang diperoleh dikampus perlu dilengkapi dengan pengalaman dilapangan.

2. Berdasarkan pengalaman, sering dijumpai antara teori dengan praktek-praktek dilapangan tidak serasi. Oleh karena itu, sebagai upaya pengkayaan keilmuan, pemahaman fenomena dilapangan sangat diperlukan.

3. Kegiatan magang di lapangan yang mempunyai sisi pembauran dengan masyarakat, juga merupakan upaya mengenalkan mahasiswa kondisi sebenarnya yang ada di pemerintahan desa/kelurahan.

Dalam pelaksanaan magang tahun 2015/2016 ini mahasiswa ditempatkan di beberapa tempat usaha, kantor Desa/Kelurahan serta terbuka kemungkinan instansi-instansi lainnya. Khusus untuk di kantor Desa/Kelurahan mahasiswa akan membantu tugastugas Sekretaris Desa/Kelurahan.

Pertimbangan pemilihan Sekretariat Desa/Kelurahan, adalah :

1. Pemerintahan Desa/Kelurahan merupakan unit kerja pemerintahan terendah yang memiliki struktur organisasi yang sederhana tetapi memiliki fungsi yang kompleks.

2. Pemerintahan Desa/Kelurahan merupakan unit pelaksana pelayanan publik yang berhadapan langsung dengan masyarakat (customer).

3. Penempatan Mahasiswa di Desa/Kelurahan berhadapan langsung dengan masyarakat, sehingga memberi dampak positif terhadap upaya memberikan pemahaman kepada Mahasiswa dalam penyelenggaraan pemerintahan. Berdasarkan pertimbangan tersebut diatas, fungsi magang tersebut utamanya adalah sebagai wahana memperkaya atau melengkapi khasanah pengetahuan dan pengalaman pemerintahan bagi Mahasiswa melalui kegiatan empirik di Desa/kelurahan. 


\subsection{Konsep Magang}

Pada dasarnya, magang merupakan proses belajar dengan cara mengikuti apa yang dikerjakan oleh orang lain yang dipandang telah cukup memiliki kemampuan dan pengalaman kerja dibidangnya. Oleh karena itu dapat di rumuskan 3 (tiga) kunci dalam filosofi magang, yaitu :

1. Apa yang dilihat ; merupakan proses magang pada tahap awal yaitu memahami dan mendalami penyelenggaraan pemerintahan desa, baik kelembagaan, tugas, fungsi, mekanisme, potensi kondisi dan sebagainya.

2. Apa yang dikerjakan ; merupakan tahap kedua yaitu ikut melakukan kegiatan yang dilakukan oleh aparat pemerintahan desa/kelurahan terutama Sekretaris, terutama dibidang administrasi pemerintahan Desa/Kelurahan. Sasaran yang akan dicapai adalah keterampilan.

3. Apa yang diperoleh ; merupakan proses magang pada tahap ketiga yaitu bagaimana pelaku mampu mengambil manfaat dari kegiatan-kegiatan yang telah dilakukan.

Sasaran yang akan dicapai dalam tahapan ini adalah kemampuan pelaku magang dalam merumuskan pengetahuan/pengalaman baru bagi dirinya dari apa yang dilihat dan dilakukan.

Oleh karena itu, dalam pelaksanaan magang akan dilakukan dengan pendekatan sebagai berikut :

1. Emperical Rasional Strategy : pendekatan ini didasarkan kepada pendekatan yang beranjak pada pengalaman/kondisi obyektif secara rasional yang dapat diterima oleh berbagai pihak ;

2. Normatif Reeducatif Strategy : ini berarti bahwa dalam pelaksanaan magang, perlu memperhatikan nilai, norma dan aturan yang berlaku di masyarakat ;

3. Partisipatif : pendekatan ini didasarkan atas keterlibatan phisik, mental dan tenaga yang bersangkutan dalam kegiatan yang dilakukan oleh pemerintah desa/kelurahan dan masyarakat ;

4. Institutionalistis : pendekatan yang mempertimbangkan keterkaitan dengan lembaga-lembaga/organisasi secara koordinasi, sinkronisasi dan harmonisasi.

\subsection{Maksud dan Tujuan}

Maksud kegiatan magang Mahasiswa di Pemerintahan Desa/Kelurahan, adalah sebagai upaya membekali Mahasiswa untuk siap terjun ke masyarakat, melalui kegiatan magang yang dibimbing langsung oleh Dosen Pembimbing dan aparat pemerintahan desa, khususnya Sekretaris Desa/Kelurahan.

Tujuan umum penyelenggaraan magang adalah : 
1. Memberikan pemahaman dan pengalaman kepada Mahasiswa mengenai aktivitas-aktivitas kepemerintahan, pembangunan dan kemasyarakatan di Desa/kelurahan ;

2. Memberikan kemampuan kepada Mahasiswa untuk melakukan/memperagakan/mengikuti aktivitas manajerial kepemerintahan di lapangan ;

3. Memberikan kemampuan kepada Mahasiswa untuk melakukan pengabdian intelektual dan keterampilan kepada masyarakat ;

4. Memberikan kemampuan kepada Mahasiswa untuk melakukan analisis potensi dan masalah yang ada di Desa/kelurahan serta konsep pemecahannya. Kemampuan analisis seperti ini harus dapat di internalisasikan kepada aparataparat pemerintahan Desa/Kelurahan;

5. Memberikan rangsangan bagi segenap aparat Desa/Kelurahan dalam upaya ikut serta mensukseskan pelaksanaan pemerintahan dan pembangunan di Desa/Kelurahan nya.

\subsection{Sasaran Magang ( Output )}

Pada dasarnya kedudukan Mahasiswa dalam program magang adalah sebagai pegawai yang diberdayakan dan diperbantukan pada Sekretariat Desa/Kelurahan. Mahasiswa dilapangan bertugas dan tidak terbatas hanya membantu Sekretaris Desa/Kelurahan dalam melaksanakan tugas-tugasnya setiap hari.

Sasaran program magang atau output magang adalah :

1. Mahasiswa dapat mengetahui dan memahami secara rinci tugas dan fungsi Sekretaris Desa/Kelurahan.

2. Mahasiswa dapat mengetahui instrumen kerja Sekretaris Desa/Kelurahan dan pemerintahan Desa pada umumnya.

3. Mahasiswa mampu melaksanakan tugas-tugas administrasi yang menjadi tugas Sekretaris Desa/Kelurahan.

4. Mahasiswa mampu melaksanakan tugas-tugas lain yang berkaitan dengan penyelenggaraan pemerintahan Desa/Kelurahan.

5. Mahasiswa mampu memberikan pembekalan kepada seluruh aparatur Desa/Kelurahan bagaimana merencanakan program pembangunan partisipatif di desa sebagai pendekatan pembangunan dari bawah (bottom up) dengan teknik pemetaan swadaya melalui kajian-kajian sederhana.

6. Mahasiswa mampu melakukan pembauran dengan masyarakat dengan baik.

Kegiatan Kesekretariatan dan Administrasi yang dilaksanakan Mahasiswa antara lain yaitu :

- Pembuatan buku-buku administrasi desa yang tidak ada seperti buku Data Tuna, Data Fakir Miskin, Jompo, dll. 
- Pengisian buku-buku administrasi desa yang sudah ada akan tetapi masih belum diisi.

- Pengisian papan monografi desa

- Membantu Pembuatan Visi dan Misi Desa, serta program-program dan sasaran dari perwujudan visi dan misi tersebut.

- Membantu pembuatan APB Desa, Peraturan Desa dan Rencana Kerja Desa.

- Membantu merekap data wajib Pajak Bumi dan Bangunan (PBB).

- Memfasilitasi aparat desa dalam melengkapi barang-barang yang harus ada dalam kantor desa (misalnya Bendera Merah Putih, Burung Garuda, Lambang Propinsi dan Lambang Kabupaten, Peta Desa, Nama Ruangan, Nama Meja dll).

- Membantu pendistribusian Beras Miskin (RASKIN)

- Dan lain-lain.

Sedangkan untuk menginternalisasikan pemahaman tentang perencanaan pembangunan partisipatif di desa. Pembekalan aparatur desa akan menggunakan pemetaan swadaya masyarakat secara sederhana dengan teknik-teknik kajian yang disesuaikan dengan kebutuhan di desa, antara lain : Teknik Pemetaan, Teknik Bagan Arus, Teknik Transek, Teknik Bagan Hubungan Kelembagaan (Diagram Venn), Teknik Matriks Rangking, dll (A. D. Mustanir 2016)(A. Mustanir and Yasin 2018)(Mustanir, Ahmad; Abadi 2016)(Barisan, Ramadhan, and Mustanir 2017)(A. Mustanir and Rusdi 2019)(A. Mustanir 2016)(A. Mustanir, Justira, et al. 2018)(Mustanir, Ahmad; Barisan, Barisan; Hamid 2017)(A. Mustanir and Jaya 2016)(A. Mustanir and Lubis 2017)(A. Mustanir 2017a)(A. Mustanir 2018b)(A. Mustanir 2017b)(Irwan et al. 2019)(A. Mustanir 2018a)(Latif et al. 2019)(A. Mustanir, Abadi, and Nasri 2016)(A. Mustanir and Jusman 2016)(Razak et al. 2018)(Akhmad, Mustanir, and Ramadhan 2018)(A. Mustanir and Razak 2017)(A. Mustanir, Ali, and Yasin 2018)(A. Mustanir, Yasin, et al. 2018)(Damis Dadda et al. 2019)(Ramadhan and Mustanir 2017)(A. Mustanir, n.d.).

Demikian semoga bermanfaat.

Berikut daftar-daftar referensi yang dapat menjadi rujukan saat kegiatan magang.

\section{Bibliography}

Akhmad, Israwaty, Ahmad Mustanir, and Muhammad Rohady Ramadhan. 2018. "Pengaruh Pemanfaatan Tekhnologi Informasi Dan Pengawasan Keuangan Daerah Terhadap Kualitas Laporan Keuangan Kabupaten Enrekang." In Prosiding Konferensi Nasional Ke-7 Asosiasi Program Pascasarjana Perguruan Tinggi Muhammadiyah Aisyiyah (APPPTMA). Jilid 2. Sosial Politik Dan Ekonomi, 89-103. http://asosiasipascaptm.or.id/index.php/publikasi/konferensi-appptm-ke-7meningkatkan-kualitas-dan-kuantitas-jurnal-ilmiah.

Barisan, Barisan, Muh Rohady Ramadhan, and Ahmad Mustanir. 2017. "Sidenreng Rappang Versus Masyarakat Ekonomi Asean." In The 2nd Journal of Government and Politics International Conference, II:258 - 262. Yogyakarta: Penerbit Program Pascasarjana Universitas Muhammadiyah Yogyakarta. http://jksg.umy.ac.id/proceeding-2nd-jgp/.

Damis Dadda, Andi, Ahmad Mustanir, Andi Nilwana, and Jamaluddin Ahmad. 2019. 
"Pengaruh Kepemimpinan Lurah Perempuan Terhadap Stabilitas Kamtibmas Di Kelurahan Rappang Kabupaten Sidenreng Rappang." In Konferensi Nasional Ke-8 Asosiasi Program Pascasarjana Perguruan Tinggi Muhammadiyah Aisyiyah (APPPTMA), 378-83. Medan: Program Pascasarjana Universitas Muhammadiyah Yogyakarta. http://asosiasipascaptm.or.id/index.php/publikasi/prosidingkonferensi-nasional-appptma-ke-8.

Irwan, Irwan, Adam Latif, Sofyan Sofyan, Ahmad Mustanir, and Fatimah Fatimah. 2019. "Gaya Kepemimpinan, Kinerja Aparatur Sipil Negara Dan Partisipasi Masyarakat Terhadap Pembangunan Di Kecamatan Kulo Kabupaten Sidenreng Rappang." MODERAT: Jurnal IImiah IImu Pemerintahan Universitas Galuh Ciamis 5 (1): 3243. https://jurnal.unigal.ac.id/index.php/moderat/article/view/1900.

Latif, Adam, Irwan Irwan, Muhammad Rusdi, Ahmad Mustanir, and Muh Sutrisno. 2019. "Partisipasi Masyarakat Dalam Pembangunan Infrastruktur Di Desa Timoreng Panua Kecamatan Panca Rijang Kabupaten Sidenreng Rappang." MODERAT: Jurnal IImiah IImu Pemerintahan Universitas Galuh Ciamis 5 (1): 1-15. https://jurnal.unigal.ac.id/index.php/moderat/article/view/1898.

Mustanir, Ahmad; Abadi, Partisan. 2016. "PARTISIPASI MASYARAKAT DALAM MUSYAWARAH RENCANA PEMBANGUNAN DI KELURAHAN KANYUARA KECAMATAN WATANG SIDENRENG KABUPATEN SIDENRENG RAPPANG." Jurnal Politik Profetik 5 (2): 247-61.

http://journal.uinalauddin.ac.id/index.php/jpp/article/viewFile/4347/3986.

Mustanir, Ahmad; Barisan, Barisan; Hamid, Hariyanti. 2017. "Participatory Rural Appraisal As The Participatory Planning Method Of Development Planning." In Indonesian Association for Public Administration (IAPA) International Conference Towards Open Government: Finding the Whole Government Approach, edited by Philipus Keban Nanang Haryono, Agie Nugroho Soegiono, Putu Aditya Ferdy Ariawantara, 77-84. Surabaya: The Faculty Of Social And Political Science Universitas Airlangga. http://conference.unair.ac.id/index.php/IAPA/iapa2017.

Mustanir, Ahmad; Darmiah. 2016. "IMPLEMENTASI KEBIJAKAN DANA DESA DAN PARTISIPASI MASYARAKAT DALAM PEMBANGUNAN DI DESA TETEAJI KECAMATAN TELLU LIMPOE KABUPATEN SIDENRENG RAPPANG." Jurnal Politik Profetik 04 (2): 225-38. http://journal.uin-alauddin.ac.id/index.php/jpp/article/view/2749.

Mustanir, Ahmad. n.d. "Pemberdayaan Masyarakat Kewirausahaan Entrepreneurship Community Empowerment."

. 2016. "Perencanaan Mewujudkan Kehidupan Pemerintahan Dan Sosial Yang Islami Di Desa Tonrong Rijang Kabupaten Sidenreng Rappang." Prosiding Seminar Nasional, Reformasi Dan Inovasi Tata Kelola Pemerintahan, 289 - 307. https://www.researchgate.net/publication/330101808_Perencanaan_Mewujudkan_ Kehidupan_Pemerintahan_dan_Sosial_Yang_Islami_di_Desa_Tonrong_Rijang_Kabu paten_Sidenreng_Rappang.

— 2017a. "Deskripsi Tentang Keamanan Di Gedung Dan Jalanan Kota Kuala Lumpur." Kuala Lumpur. https://www.researchgate.net/publication/331064740_Deskripsi_Tentang_Keaman an_Di_Gedung_dan_Jalanan_Kota_Kuala_Lumpur.

_. 2017b. "Pemberdayaan Badan Usaha Milik Desa Melalui Kelompok Ekonomi Kewirausahaan Secara Partisipatif." https://www.researchgate.net/publication/331065123_Pemberdayaan_Badan_Usah a_Milik_Desa_Melalui_Kelompok_Ekonomi_Kewirausahaan_Secara_Partisipatif. 
2018a. "Pemanfaatan Teknologi Informasi Dalam Optimalisasi Pelayanan Publik Dan Potensi Desa Sereang." https://www.researchgate.net/publication/331064206_Pemanfaatan_Teknologi_Inf ormasi_Dalam_Optimalisasi_Pelayanan_Publik_dan_Potensi_Desa_Sereang.

_ 2018b. "Pemberdayaan Perempuan Anggota Badan Usaha Milik Desa Dengan Pemanfaatan Lahan Kebun Bibit Desa." Rappang. https://www.researchgate.net/publication/331071158_Pemberdayaan_Perempuan _Anggota_Badan_Usaha_Milik_Desa_dengan_Pemanfaatan_Lahan_Kebun_Bibit_D esa.

Mustanir, Ahmad, Partisan Abadi, and A Nasri. 2016. "Participation of Ethnic Community Towani Tolotang in Deliberation of Development Plan." In International Conference on Ethics in Governance (ICONEG 2016), 84:356 - 359. Makassar: Atlantis Press. https://doi.org/10.2991/iconeg-16.2017.79.

Mustanir, Ahmad, Akhwan Ali, and Akhmad Yasin. 2018. "Transect on Participatory Development Planning in Sidenreng Rappang Regency." In IOP Conference Series: Earth and Environmental Science. Maka.

Mustanir, Ahmad, and Irfan Jaya. 2016. "PENGARUH KEPEMIMPINAN DAN BUDAYA POLITIK TERHADAP PERILAKU PEMILIH TOWANI TOLOTANG DI KECAMATAN MARITENGngAE KABUPATEN SIDENRENG RAPPANG." Jurnal Politik Profetik 04 (1): 84-97. http://journal.uin-alauddin.ac.id/index.php/jpp/article/view/2741\# .

Mustanir, Ahmad, and Jusman. 2016. "IMPLEMENTASI KEBIJAKAN DAN EFEKTIVITAS PENGELOLAAN TERHADAP PENERIMAAN RETRIBUSI DI PASAR LANCIRANG KECAMATAN PITU RIAWA KABUPATEN SIDENRENG RAPPANG." Jurnal Ilmiah Akmen $\quad 13 \quad$ (3): $\quad$ 542-58. indonesia.ac.id/index.php/akmen/article/view/69.

Mustanir, Ahmad, Nur Justira, Kamaruddin Sellang, and Andi Ilham Muchtar. 2018. "Democratic Model On Decision-Making At Deliberations Of Development Planning." International Conference on Government Leadership and Social Science (ICOGLASS). Demanding Governance Accountability and Promoting Democratic Leadership for Public Welfare Achievement, 110 - 115. https://www.researchgate.net/publication/330090538_Democratic_Model_On_Deci sion-Making_At_Deliberations_Of_Development_Planning.

Mustanir, Ahmad, and Sandi Lubis. 2017. "Participatory Rural Appraisal in Deliberations of Development Planning." In International Conference On Democracy, Accountability, and Governance (ICODAG 2017), 163:316-19. Pekanbaru: Atlantis Press. https://doi.org/10.2991/icodag-17.2017.60.

Mustanir, Ahmad, and M Rais Rahmat Razak. 2017. "Nilai Sosial Budaya Pada Partisipasi Masyarakat Etnik Towani Tolotang Dalam Musyawarah Rencana Pembangunan." In Prosiding Konferensi Nasional Ke-6 Asosiasi Program Pascasarjana Perguruan Tinggi Muhammadiyah Aisyiyah (APPPTMA), 1-7. Pare Pare: Program Pascasarjana Universitas Muhammadiyah

Yogyakarta. http://asosiasipascaptm.or.id/index.php/publikasi/prosiding-konferensi-nasionalappptma-ke-6.

Mustanir, Ahmad, and Muhammad Rusdi. 2019. "Participatory Rural Appraisal (PRA) Sebagai Sarana Dakwah Muhammadiyah Pada Perencanaan Pembangunan Di Kabupaten Sidenreng Rappang." Prosiding Konferensi Nasional Ke-8 Asosiasi Program Pascasarjana Perguruan Tinggi Muhammadiyah Aisyiyah (APPPTMA). Medan. http://asosiasipascaptm.or.id/index.php/publikasi/prosiding-konferensi- 
nasional-appptma-ke-8.

Mustanir, Ahmad, and Akhmad Yasin. 2018. "Community Participation in Transect on Development Planning." Jurnal IImiah IImu Administrasi Publik: Jurnal Pemikiran Dan Penelitian Administrasi Publik (JIAP) 8 (2): 137-46. https://doi.org/https://doi.org/10.26858/jiap.v8i2.7994.

Mustanir, Ahmad, Akhmad Yasin, Irwan Irwan, and Muhammad Rusdi. 2018. "Potret Irisan Bumi Desa Tonrong Rijang Dalam Transect Pada Perencanaan Pembangunan Partisipatif." MODERAT: Jurnal Ilmiah IImu Pemerintahan 4 (4): 1-14. https://jurnal.unigal.ac.id/index.php/moderat/article/view/1775.

Ramadhan, Muhammad Rohady, and Ahmad Mustanir. 2017. "Sidenreng Rappang Versus Masyarakat Ekonomi Asean." In . http://jksg.umy.ac.id/wpcontent/uploads/2017/08/Proceding-The-2nd-Journal-of-Government-and-Politics2017.compressed.pdf.

Razak, Muhammad Rais Rahmat, Mansyur Dahong, Jamaluddin Ahmad, Herman Dema, and Ahmad Mustanir. 2018. "The Effect of Siri's Marriage on Government Administration." International Journal of Sciences: Basic and Applied Research (IJSBAR)

42

171-84. http://gssrr.org/index.php?journal=JournalOfBasicAndApplied\&page=article\&op=vi ew\&path\%5B\%5D=9484. 